\title{
Single-Channel $\mathrm{K}^{+}$Currents Recorded from the Somatic and Dendritic Regions of Cerebellar Purkinje Neurons in Culture
}

\author{
D. L. Gruol, T. Jacquin, ${ }^{a}$ and A. J. Yool ${ }^{\mathrm{b}}$ \\ Department of Neuropharmacology, Research Institute of Scripps Clinic, La Jolla, California 92037
}

\begin{abstract}
Voltage-sensitive $K^{+}$channels were studied in rat cerebellar Purkinje neurons in culture using the single-channel recording technique. Recordings in the cell-attached and outsideout configuration revealed multiple voltage-sensitive $\mathbf{K}^{+}$ channel types in patches from both the somatic and the dendritic regions. $\mathrm{K}^{+}$channel types were present in all patches studied. The same channel types were observed in somatic and dendritic recordings. Channel types were identified by reversal potential, single-channel conductance, voltage sensitivity, and patterns of activity. In cell-attached patches recorded under physiological conditions, 3 channel types were identified. Mean single-channel conductances were 92,57 , and $12 \mathrm{pS}$. All 3 channel types were activated by membrane depolarization. Similar channel types were identified in inside-out and outside-out patches recorded under physiological conditions. Two additional channel types were identified in the outside-out patches, with mean singlechannel conductances of 41 and 26 pS. In cell-attached recordings under symmetrical $K^{+}$conditions, 6 channel types were identified. Mean single-channel conductances were 222, $134,39,25,14$, and $15 \mathrm{pS}$. Channel types with mean conductances of 222, 134 , and 39 pS required membrane depolarization for activation. A comparison of channel properties indicated that these channel types correlated with the 3 channel types observed in cell-attached patches under physiological conditions. The 3 smaller-conductance channel types $(25,14$, and $15 \mathrm{pS})$ were active at potentials around rest or at hyperpolarized membrane potentials. Two $\mathrm{K}^{+}$channel types (39 and 25 pS) were commonly associated with the late phase of extracellularly recorded spontaneous spike events, suggesting a functional role in the repolarizing phase of somatic and dendritic action potentials. These results demonstrate that voltage-sensitive $\mathrm{K}^{+}$channels are a prominent component of both the somatic and the dendritic membrane of the cerebellar Purkinje neuron and support the view that multiple voltage-sensitive $\mathrm{K}^{+}$channel types contribute to the membrane functions of both cellular regions in this CNS neuronal type.
\end{abstract}

\footnotetext{
Received June 27, 1990; revised Oct. 22, 1990; accepted Nov. 19, 1990.

We thank Dr. Vince Dionne for helpful discussions and comments on the manuscript. This work was supported by NIH Grant NS21777 to D.L.G. and Training Grant AA07456. T.J. was supported in part by the Fondation de l'Industrie Pharmaceutique pour la Recherche and the French Ministry Bourse Lavoisier.

Correspondence should be addressed to Dr. Donna Gruol, Department of Neuropharmacology, Research Institute of Scripps Clinic, 10666 North Torrey Pines Road, La Jolla, CA 92037.

a Present address: CNRS LPN1, Gif sur Yvette 91190, France.

b Present address: Beckman Center, Department of Molecular and Cellular Physiology, Stanford University Medical Center, Stanford, CA 94305.

Copyright (C) 1991 Society for Neuroscience 0270-6474/91/111002-14\$03.00/0
}

The electrophysiological properties of mammalian CNS neurons are established by the type and cellular distribution of ionic conductances present in the neuronal membrane. Considerable information is now available about these conductances due to the development of in vitro preparations such as isolated brain slices and tissue culture preparations. These preparations are suitable for long-term electrophysiological studies using intracellular and voltage-clamp techniques. However, a full characterization of the ionic conductances has been limited by 2 technical problems: (1) the large dendritic structure of many CNS ncurons creates space-clamp problems that confound voltage-clamp studies, and (2) selective ion channel blockers are not available for all ion channel types. Thus, we have turned to the single-channel recording technique as a means to further explore the ionic conductances that contribute to the physiological properties of CNS neurons.

To date, few single-channel studies of CNS neurons have appeared. Consequently, relatively little is known about the specific ion channel types that mediate CNS neuronal excitability. Such studies have been hampered by the heterogeneous nature of CNS tissue, the varied electrical properties of the resident neuronal types, the limited availability of cell-specific markers, and the difficulty in maintaining CNS neurons under appropriate in vitro conditions. To circumvent these problems, we have focused on a culture model system, modified organotypic cultures of cerebellar neurons, where single-channel recordings from an identified CNS neuronal type, the cerebellar Purkinje neuron, are possible (Gruol, 1983; Yool et al., 1988).

In culture, Purkinje neurons express many of the physiological properties described for Purkinje neurons in vivo or in the isolated brain slice preparation, though the extent of the similarity appears to depend somewhat on the culture methods (Bossu et al., 1988; Kapoor et al., 1988; Hockberger et al., 1989). In our culture preparation, the Purkinje neurons exhibit high-frequency firing patterns and pacemaker activity and generate several types of spike events (Gruol, 1983; Gruol and Franklin, 1987). These properties reflect properties described for Purkinje neurons in vivo (Eccles et al., 1967; Woodward et al., 1969) or in the in vitro slice preparation (Llinas and Sugimori, 1980b; Hounsgaard and Nicholson, 1983; Hounsgaard and Midtgaard, 1988). The similarity in properties indicates that many of the intrinsic ionic conductances important for normal membrane functions in vivo are expressed in the culture preparation, where they can be examined using high-resolution electrophysiological techniques such as the single-channel recording technique.

Studies using intracellular, voltage-clamp, and $\mathrm{Ca}^{2+}$ imaging techniques have shown that a variety of voltage-sensitive conductances, including several $\mathrm{K}^{+}$conductances, are involved in the production of the complex membrane events generated by 
the Purkinje neuron (Llinas and Sugimori, 1980a,b; Crepel and Penit-Soria, 1986; Gruol and Franklin, 1987; Ross and Werman, 1987; Bossu et al., 1988, 1989a,b; Hounsgaard and Midtgaard, 1988; Tank et al., 1988; Gahwiler and Llano, 1989; Hockberger et al., 1989). In the present study, we have extended these studies by examining the cellular membrane of the Purkinje neuron for $\mathrm{K}^{+}$channel types.

$\mathrm{K}^{+}$conductances are known to play a central role in the excitability of CNS neurons. $\mathrm{K}^{+}$conductances contribute to the resting membrane potential, the repolarization of the membrane during action potential generation, the production of intrinsic pacemaker or bursting activity, and the transduction of synaptic signals elicited by certain transmitters (Rudy, 1988). Based on kinetic properties, voltage sensitivity, and sensitivity to ion channel blockers, 4 main classes of $\mathrm{K}^{+}$conductances have been identified: delayed rectifiers, inward rectifiers, transient currents, and $\mathrm{Ca}^{2+}$ activated $\mathrm{K}^{+}$conductances (Thompson and Aldrich, 1980). Distinct $\mathrm{K}^{+}$channel types are thought to underlie each conductance class. Direct dcmonstration of multiple $\mathrm{K}^{+}$channcl types and, in some cases, a correlation of channel types with specific membrane conductances have come from studies using the single-channel recording technique. In the majority of these studies, peripheral neuronal cells, non-neuronal cells, cell lines, or invertebrate preparations were examined (Rudy, 1988). Relatively little information is available on the $\mathrm{K}^{+}$channel types that contribute to the excitability of mammalian CNS neurons.

One advantage of our culture preparation for single-channel studies is that the somatic and dendritic regions can be clearly visualized, enabling recordings from both cellular regions. An examination of dendritic properties in the Purkinje neuron is of particular interest because active membrane conductances have been observed in intracellular, voltage-clamp, and $\mathrm{Ca}^{2+}$ imaging studies of the dendritic region (Llinas and Sugimori, 1980b; Gruol, 1986; Ross and Werman, 1987; Tank et al., 1988; Bossu et al., 1989a; Hockberger et al., 1989). Recently, Bossu et al. (1989b) have shown that $\mathrm{Ca}^{2+}$ channel types are present in dendrites of Purkinje neurons using the single-channel recording technique.

The presence of active conductances in the dendritic region, the main site of synaptic input to CNS neurons, has important functional implications for the transduction and integration of synaptic signal. In the Purkinje neuron, dendritic $\mathrm{Ca}^{2+}$ conductances have been associated with dendritic spike generation, the production of endogenous activity patterns, and membrane depolarization elicited by synaptic events (Llinas and Sugimori, 1980b; Tank et al., 1988). A question then arises as to how the depolarizing actions of the dendritic $\mathrm{Ca}^{2+}$ conductances are controlled. Voltage-sensitive dendritic $\mathrm{K}^{+}$channels could subserve this function. Thus, we have examined both the somatic and the dendritic region of the Purkinje neuron for the presence of $\mathrm{K}^{+}$channel types. Results from these studies demonstrate that multiple $\mathrm{K}^{+}$channel types are present in both the somatic and the dendritic regions of this CNS neuronal type.

\section{Materials and Methods}

Culture methods. Modified organotypic cultures were prepared from the cortical region of fetal rat cerebella according to methods described previously (Gruol, 1983). Briefly, the cortical regions of 20-d-gestation rat embryo cerebella were minced, gently triturated, plated on poly-Dlysine coated culture dishes containing culture medium, and incubated at $37^{\circ} \mathrm{C}$ in a $\mathrm{CO}_{2}$ incubator. The cultures were maintained for up to 1 month with biweekly medium change. Brief treatment with 5-fluorodeoxyuridine (40-80 $\mu \mathrm{M})$ retarded the growth of non-neuronal cells.
Cultures prepared by this method contain the 6 neuronal types present in the cortical region of cerebellum in vivo: the Purkinje neuron and basket, stellate, Golgi, Lugaro, and granule cells. The Purkinje neurons are the largest neuronal type in culture and can be distinguished from the other neuronal types by their unique morphology and selective immunostaining (Gruol and Crimi, 1988). The Purkinje neurons are immature at the time of plating but complete their morphological, physiological, and synaptic maturation during the culture period (Gruol and Franklin, 1987).

Electrophysiological methods. Purkinje neurons maintained in culture for more than 2 weeks and expressing well-developed somatic and dendritic structures were studied. The large soma (20-25 $\mu \mathrm{M}$ in diameter) and thick dendritic processes (3-5 $\mu \mathrm{M}$ in width) are suitable for wholecell and single-channel recordings. Recordings were made from both cellular regions according to established procedures (Hamill et al., 1981; Yool et al., 1988). Dendritic recordings were made in the thickest region, which varied among the dendrites studied (e.g., along the dendritic shaft, at branch points, or at the distal end). Gigohm seals were obtained in approximately $10 \%$ of the somatic and dendritic recordings attempted. Seal resistances ranged from 1 to $10 \mathrm{G} \Omega$. The low success rate for obtaining high-resistance seals in this preparation appears to be due to the expression of surface components that interfered with seal formation. Enzyme treatments to clean the neuronal surface point to recording were ineffective or damaged the neurons and were not used. The difficulty in obtaining $G \Omega$ seals prevented a detailed study of channel distribution.

Electrodes were prepared from hematocrit glass (Fisher), coated with Sylgard and fire-polished. Useful recordings were obtained with electrodes in the range of 5-6 M $\Omega$. Lower-resistance electrodes rarely formed $\mathrm{G} \Omega$ seals; higher-resistance electrodes produced unstable recordings. The electrodes contained physiological saline or a high- $\mathrm{K}^{+}$saline of the following composition (mM): $\mathrm{KCl}$ or $\mathrm{K}^{+}$-gluconate, $144 ; \mathrm{NaCl}, 8 ; \mathrm{MgCl}_{2}$, 2; glucose, 10; HEPES-NaOH, $10(\mathrm{pH}, 7.3)$; EGTA, 1 ; and $\mathrm{CaCl}_{2}$ to give free $\mathrm{Ca}^{2+}$ concentrations of 0.1 or $0.5 \mu \mathrm{M}$. The bath contained physiological saline consisting of the following (mM): $\mathrm{NaCl}, 140 ; \mathrm{KCl}$, $3.5 ; \mathrm{KH}_{2} \mathrm{PO}_{4}, 0.4 ; \mathrm{Na}_{2} \mathrm{HPO}_{4}, 1.25 ; \mathrm{CaCl}_{2}, 2.2 ; \mathrm{MgSO}_{4}, 2 ;$ glucose, 10 ; and IILPCS-NaOII, 10 (pII, 7.3). Recordings were made with the List EPC-7 patch-clamp amplifier (Medical Systems, Inc.) or the Axopatch (Axon Instruments). Experiments were performed at room temperature $\left(\sim 21^{\circ} \mathrm{C}\right)$.

Data acquisition and analysis. The use of the single-channel recording technique to examine ion channel types in Purkinje neurons was complicated by the fact that most patches contained multiple channels of the same and different types. Conventional analysis methods involving short-duration voltage commands were not useful with these complex recordings because channel activity elicited at one membrane potential could not be correlated unequivocally with events elicited at other membrane potentials. Consequently, an analysis procedure based on the use of long-duration voltage commands (seconds to minutes) combined with visual, manual, and computer evaluation of the data was used. With such an approach, channel types exhibiting strong inactivation at all potentials would not be detected. However, considerable channel activity was observed under these conditions, indicating that in the Purkinje neuron several channel types do not fall into this category. Of these, channel types selective for $\mathrm{K}^{+}$were identified by their reversal potential under different ionic conditions. All $\mathrm{K}^{+}$channel types studied under these conditions were active for the duration of the applied voltage command but were not active at all applied potentials.

All single-channel data were recorded on FM tape (Racal Store 4DS recorder) for off-line analysis. For manual analysis, taped recordings of channel activity obtained at different membrane potentials were played back onto a polygraph recorder at reduced tape specds and varying polygraph speeds to display the channel events at different time bases. The polygraph recordings were used for within-patch and across-patch comparisons. At each potential studied, channel events were measured and the characteristics of the activity noted. Characteristics used to distinguish channel types at the same and different membrane potentials included the amplitude and relative durations of the open states, the amount of noise in the open state, the patterns of activity (i.e., single openings vs. clusters of openings, continuous vs. intermittent activity patterns), the I-V relation, and the potentials at which the channels were active.

For computer analysis, the same taped data were filtered at $1-3 \mathrm{kHz}$ (Bessel filter, 3-dB cutoff), digitized at sampling rates of $60-400 \mu \mathrm{sec}$, and analyzed with a PDP $11 / 73$ computer (Indec System) using semi- 
A1

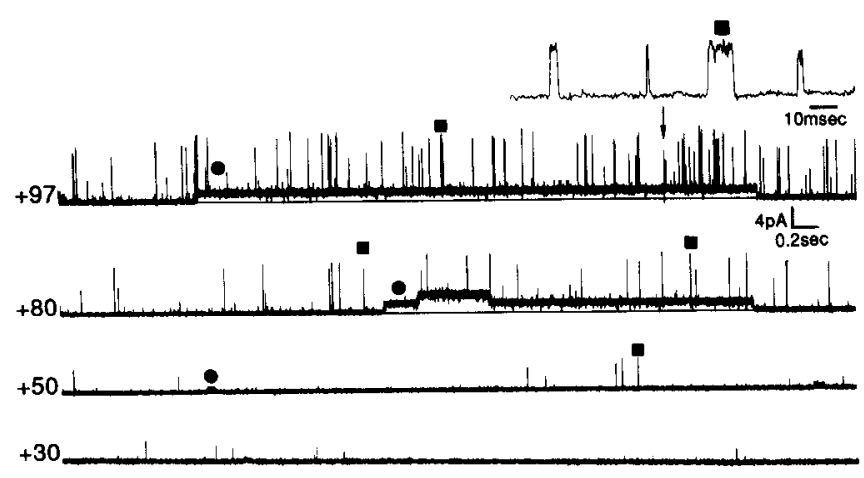

B1

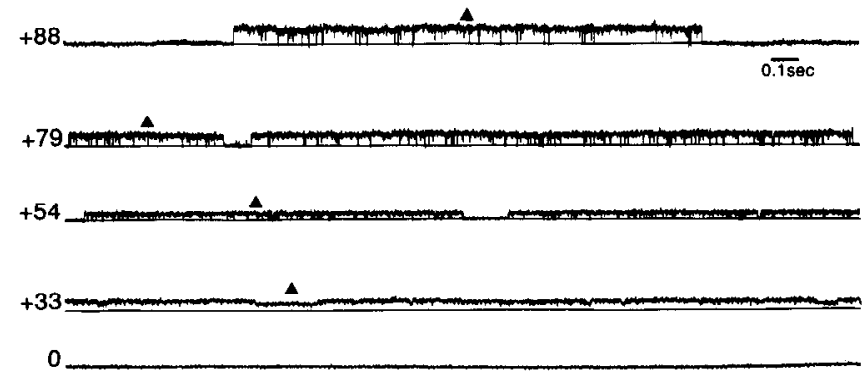

A2

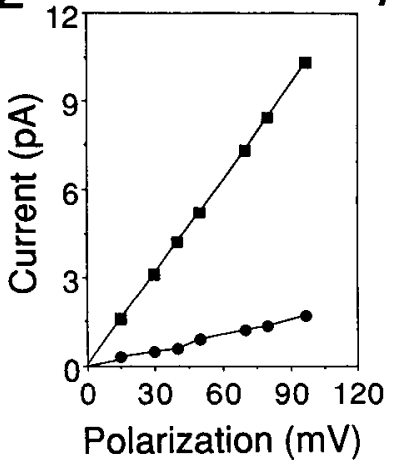

B2

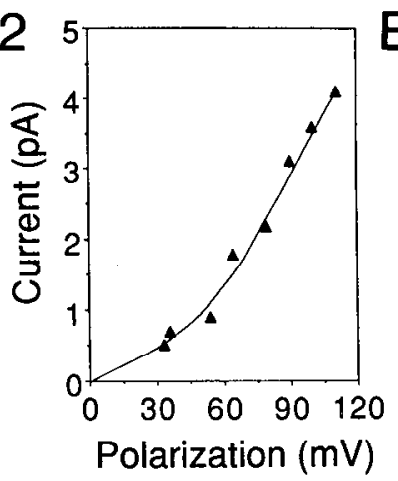

A3
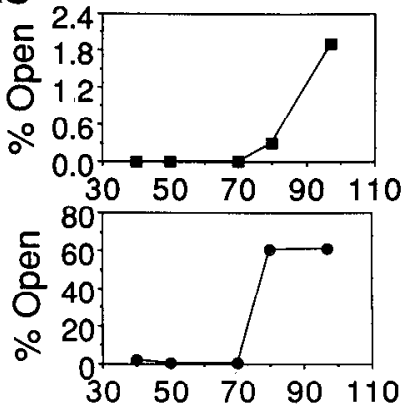

Polarization $(\mathrm{mV})$

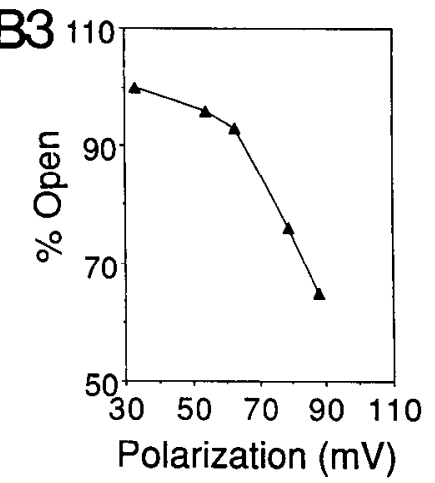

Figure 1. Voltage-sensitive single-channel activity of $\mathrm{K} 1, \mathrm{~K} 2$, and $\mathrm{K} 3$ channel types in ccll-attached recordings under physiological ionic conditions. Some events are labeled according to channel type $(\mathrm{K} 1,-\mathrm{K} 2, \mathrm{~A} ; \mathrm{K} 3, \bullet) . A 1$, Polygraph recordings of single-channel events activated by depolarizing voltage commands in a somatic patch. The large-amplitude, brief openings reflect activity of the K1 channel type. The long-duration, smallamplitude openings reflect activity of the K3 channel type. The expanded recording at the top shows, at a faster time base, some of the openings (arrow) of the K1 channel type during the $97-\mathrm{mV}$ command. A2, Current-voltage relationship. Slope conductances were $105 \mathrm{pS}$ for the K1 ( channel type and $17 \mathrm{pS}$ for the K3 (O) channel type. A3, The percent of sample time spent in the open state at different membrane potentials. Top graph, K1 channel type; bottom graph, $\mathrm{K} 3$ channel type. The 2 channel types were active over similar voltage ranges. At potentials where activity was observed, the $\mathrm{K} 3$ channel type spent considerably more time in the open state than did the K1 channel type. $B I$, Polygraph recordings showing voltage-sensitive activity of the $\mathrm{K} 2$ type in a cell-attached dendritic patch. $B 2$, Current-voltage relationship. The single-channel conductance was $55 \mathrm{pS}$, measured in the linear range of the I-V curve between $60-$ and $120-\mathrm{mV}$ polarizations. B3, The percent of sample time spent in the open state at different membrane potentials. The channel was most active at depolarizations of $30-50 \mathrm{mV}$, where double-level openings with few excursions to baseline current level were observed. At more depolarized potentials, channel activity decreased. In these and all other figures of cellattached recordings, membrane polarization refers to the magnitude of the applied voltage command: 0 polarization is resting membrane potential $(\sim-60 \mathrm{mV})$, positive values denote membrane depolarizations, and negative values denote membrane hyperpolarizations. In all figures, the channel activity shown is representative of that observed during the long-duration $(>5 \mathrm{sec}$ ) voltage commands.

\section{Table 1. $\mathrm{K}^{+}$channel types in cerebellar Purkinje neurons under different recording conditions ${ }^{a}$}

$\mathrm{K} 1$

$$
\begin{aligned}
& 92 \pm 5(12) \\
& 1.4 \pm 0.2(12)
\end{aligned}
$$$$
80
$$

Percent patches with channel $(N=15)$

Outside out: physiological $\mathrm{K}^{+}$

Conductance $(\mathrm{pS})$

Mean number of channels/patch ${ }^{0}$

Percent patches with channel $(N=59)$

Cell attached: high $\mathrm{K}^{+}$

Conductance $(\mathrm{pS})$

Mean number of channels/patch ${ }^{b}$

Percent patches with channel $(N=54)$
K2

K3

$$
\begin{aligned}
& 12 \pm 1(9) \\
& 1.6 \pm 0.2(9) \\
& 60 \\
& 16 \pm 1(22) \\
& 1.4 \pm 0.1(22) \\
& 37 \\
& 39 \pm 1(31) \\
& 1.1 \pm 0.1(31) \\
& 57
\end{aligned}
$$

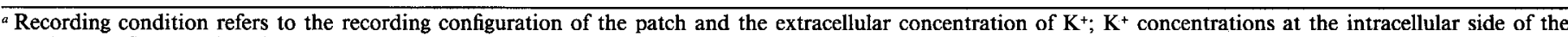

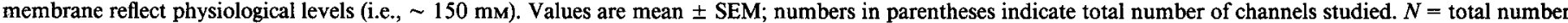
of patches studied and includes data from somatic and dendritic patches.

${ }^{b}$ Includes only patches containing the channel type. 
automated procedures and computer programs similar to those described in Leibowitz and Dionne (1984). The single-channel events were visualized on a monitor during the computer analysis, and comparisons were made to the events displayed in the polygraph recordings of the same data. Computer analysis generated (1) amplitude histograms for construction of I-V curves and frequency of activity graphs, (2) estimates of the percent of sample time spent in the open state, and (3) open-time histograms for determination of mean open times ( $\tau$ values).

Voltage sensitivity was assessed qualitatively by visual inspection of the frequency and duration of channel activity in polygraph recordings and quantitatively by the computer analysis of the frequency of channel openings or the percent of sample time spent in the open state. The frequency of channel openings was obtained by dividing the number of computer-detected channel openings at each current level by the sample duration. Only unitary events were used for this analysis. Results were similar if all openings (single and multiple) of a channel type were considered or if the data were normalized to take into account the number of channels of a particular type in the patch. The number of each channel type in a patch was estimated from simultaneous openings of the unitary events representing a channel type. Simultaneous openings were easily detected in the polygraph recordings but were also evident during computer analysis. The activity graphs were used for withinchannel comparisons at different membrane potentials and for a crosschannel comparisons at the same potential. Because of the complexity of the recordings, the kinetic properties of the channel types could not be quantitatively evaluated. Efforts to isolate selectively specific channel types with pharmacological agents were unsuccessful. Most $\mathrm{K}^{+}$channel blockers were nonselective or altered channel properties such that channel types could not be unequivocally identified.

Figures were prepared from polygraph recordings and are representative of results obtained from 108 somatic and 20 dendritic patches where sufficient data for channel identification could be obtained. To facilitate comparisons of channel types under the same and different recording conditions, channel types are initially referred to by their mean conductance values and then classified as a channel type designated by numbers ranging from $\mathrm{K} 1$ to $\mathrm{K} 8$. Mean values are expressed as mean \pm standard error of the mean and contain data from both somatic and dendritic patches. $N$ is the number of patches studied. In cell-attached recordings, the polarizing commands are referred to as applied polarization with respect to resting membrane potential ( 0 applied polarization).

\section{Results}

Channel activity in cell-attached patches recorded under physiological conditions. The somatic and dendritic membranes of the cultured Purkinje neurons were examined for $\mathrm{K}^{+}$channels first using cell-attached recordings and electrodes fillcd with physiological saline. Twelve somatic and 3 dendritic patches were studied. In all patches studied, single-channel events were infrequent at resting potential (i.e., no applied polarization) and during hyperpolarizing voltage commands. However, depolarization of the membrane evoked outward current events of several distinct amplitudes. These current events were identified as resulting from the activity of 3 voltage-sensitive $\mathrm{K}^{+}$channel types based on single-channel conductance, reversal potential, voltage sensitivity, patterns of activity, and the relative duration of the open state. Figure 1 illustrates the properties of these channei types. Mean single-channel conductances derived from the linear slope of the I-V relationships were 92,57 , and $12 \mathrm{pS}$ (Table 1). These channel types are referred to as the $\mathrm{K} 1(92 \mathrm{pS})$, $\mathrm{K} 2$ (57 pS), and K3 (12 pS) channel types. The K1 and K3 channel types were commonly observed in the cell-attached patches. The K2 channel type was only observed in 3 of the 15 patches studied. All 3 channel types were present in patches from the somatic and dendritic regions.

The K1 (92 pS) channel type required strong depolarizations $(>50 \mathrm{mV}$ ) for activation (Fig. 1). The amplitude, frequency, and duration of the unitary events increased as a function of membrane depolarization. Openings occurred at irregular intervals and ranged from $<1$ to $\sim 50 \mathrm{msec}$ in duration. The $\mathrm{K} 3(12 \mathrm{pS})$ channel type was activated by small depolarizations, where channel activity occurred in brief, infrequent bursts (Fig. 1). I ike the K1 channel type, the amplitude, frequency, and duration of the openings increased as a function of membrane potential. At strong depolarizations $(>60 \mathrm{mV})$, openings were still infrequent but prolonged (up to several seconds) in duration. Brief or incompletely resolved closures occurred during the long openings.

The K2 (57 pS) channel type was activated by small membrane depolarizations $(10-20 \mathrm{mV})$ where activity was characterized by prolonged openings that often lasted for several seconds (Fig. 1). Brief or incompletely resolved closures occurred during the long openings. Further depolarization initially increased the amplitude, frequency, and duration of the openings, with maximal activity occurring at depolarizations of $30-60 \mathrm{mV}$ from rest. At these potentials, multiple, prolonged openings with few excursions to baseline current level were observed. At more

Table 1. Continued

K4 K5 K6 K7 K8

$\begin{array}{ll}41 \pm 1(14) & 26 \pm 1(9) \\ 1.3 \pm 0.2(14) & 1.0 \pm 0(9) \\ 24 & 15\end{array}$
$25 \pm 1(31)$
$1.3 \pm 0.1(31)$

$14 \pm 1(16)$
$1.2 \pm 0.1(16)$
30

$15 \pm 1(22)$

$1.0 \pm 0.1(22)$

41 
A1

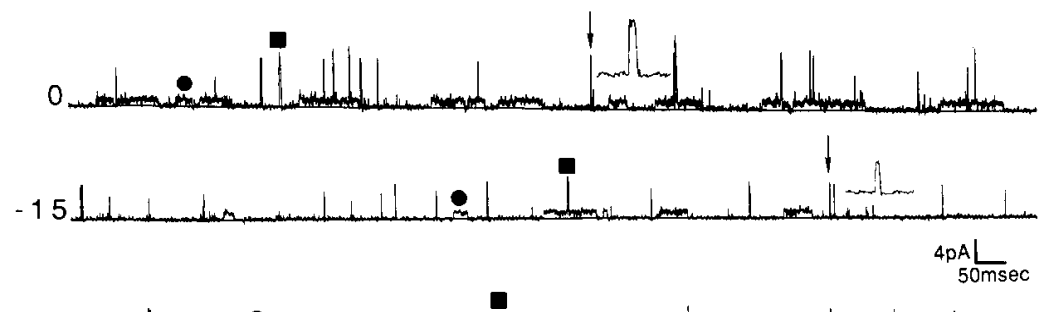

ع

B1

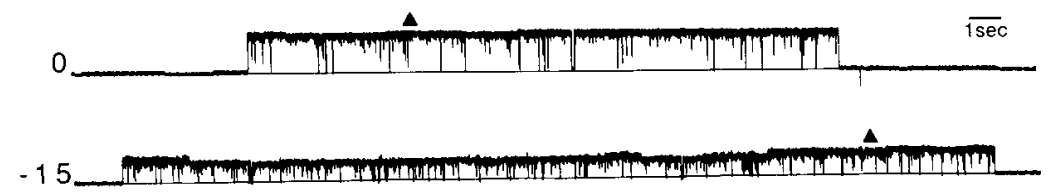

-30 m.
A2

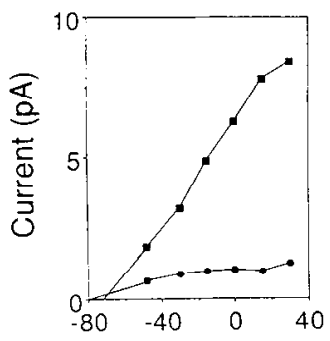

Polarization $(\mathrm{mV})$

$\mathrm{B} 2$

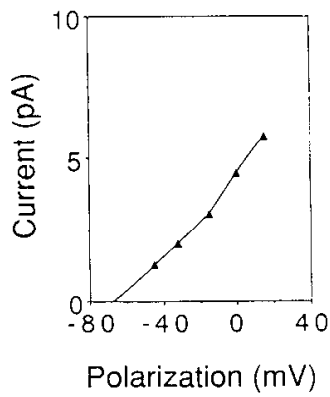

A3

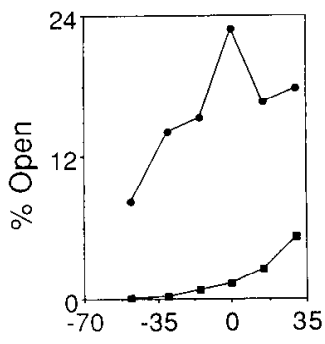

Polarization $(\mathrm{mV})$

\section{B3}

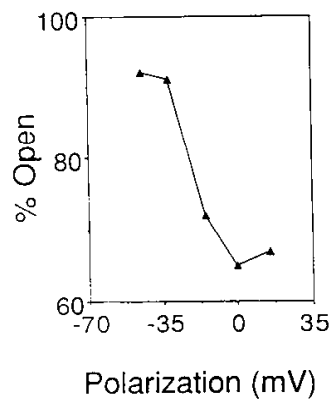

Figure 2. Voltage-sensitive single-channel activity of $\mathrm{K} 1, \mathrm{~K} 2$, and $\mathrm{K} 3$ channel types in inside-out somatic patches under physioloigcal $\mathrm{K}^{+}$conditions. The recording electrode contained physiological saline; the recording chamber contained high $\mathrm{K}^{+}$saline prepared with $\mathrm{KCl}\left(0.05 \mu \mathrm{M}\right.$ free $\left.\mathrm{Ca}^{2+}\right)$. Some channel events are labeled with symbols to designate the channel type $(\mathrm{K} 1, \mathbf{\mathrm { a }} ; \mathrm{K} 2, \mathbf{\Delta} ; \mathrm{K} 3, \mathbf{0})$. A1, Polygraph recordings of channel activity of the K1 and K3 channel types. The expanded recordings show at a faster time base some of the openings (indicated with arrows) of the K1 channcl type. $A 2$, Current-voltage relationship. Single-channel slope conductances were $100 \mathrm{pS}$ for the large-conductance channel (K1; $)$ and 21 $\mathrm{pS}$ for the small conductance channel $(\mathrm{K} 3 ; 0)$. The negative reversal potential indicates that the channel types are $\mathrm{K}^{+}$selective $\left(E_{K}=-95 \mathrm{mV} ; E_{\mathrm{Cl}}\right.$ $=3 \mathrm{mV}) . A 3$, The percent of sample time spent in the open state at different membrane potentials. The activity of both channel types increased with membrane depolarization. Bolh channel types were more active in the inside-out patch than in the cell-attachcd patch shown in Figure 1 . B1, Polygraph recordings showing single-channel activity of the K2 type at different membrane potentials in another somatic patch. Two channel types were present in the patch: the K2 channel type and a small channel type that was not studied. The apparent change in amplitude of the K2 channel type at each command potential is due to the activity of the small channel type. $A 2$, Current-voltage relationship. Single-channel slope conductance was $83 \mathrm{pS}$. The I-V relation dinciates a negative null potential, consistent with the selectivity of the channel for $\mathrm{K}^{+} . A 3$, The percent of sample time spent in the open state at different membrane potentials. Maximal activity occurred at potentials more negative than $0 \mathrm{mV}$.

depolarized potentials, where the $\mathrm{K} 1$ and $\mathrm{K} 3$ channel types were most active, the frequency of activity and the duration of the open state decreased as a function of membrane potential.

The depolarizing I-V relation for the 3 channel types often showed rectification. Most commonly, the rectification appeared as a decreased conductance at strong membrane depolarizations (not shown). Channel activity was infrequent at hyperpolarized potentials and could not be correlated with the channel events observed at depolarized potentials. Extrapolation of the linear range of the depolarizing $\mathrm{I}-\mathrm{V}$ relations gave null potentials near resting membrane potential for all 3 channel types ( $E_{\text {rev }}=-7 \pm 3 \mathrm{mV}$ polarization; $N=15$ patches). The negative reversal potential indicates a selectivity of the channel types for $\mathrm{K}^{+}$or $\mathrm{Cl}^{-}$, the 2 cellular ions having negative equilibrium potentials under physiological conditions. To distinguish between these 2 possibilities, recordings were made in the inside-out configuration, where the transmembrane ionic environment could be controlled. In these studies, the bath contained high- $\mathrm{K}^{+}$saline prepared from $\mathrm{KCl}$; the recording electrode contained physiological saline. The calculated equilibrium potential for $\mathrm{K}^{+}$was $-95 \mathrm{mV}$; the calculated equilibrium potential for $\mathrm{Cl}^{-}$was $3 \mathrm{mV}$. As shown in Figure 2, all three channel types exhibited a negative reversal potential under these conditions, identifying the channel types as $\mathrm{K}^{+}$selective.
$\mathrm{K}^{+}$channel types were a prominent component of the cellattached patches studied under physiological conditions. $\mathrm{K}^{+}$ channels were present in all patches studied, with a mean of 2.3 \pm 0.3 total channels and $1.6 \pm 0.2$ different channel types observed per patch $(N=15$; Table 1$)$.

Channel activity in cell-attached patches recorded under symmetrical $\mathrm{K}^{+}$conditions. Two difficulties were encountered in the study of $\mathrm{K}^{+}$channels under physiological conditions: (1) in many patches, channel activity occurred over a limited range of membrane potentials, making it difficult to identify unequivocally channel types, and (2) the small amplitude of the unitary events at some potentials (especially near the reversal potential) prevented computer analysis. The use of high- $K$ ' saline in the recording electrode, to provide a symmetrical $\mathrm{K}^{+}$environment across the patch, alleviated some of these problems. Channel activity was more extensive under the symmetrical $\mathrm{K}^{+}$conditions and could be detected over a wider range of membrane potentials, facilitating identification of $\mathrm{K}^{+}$channel types. However, multiple channel types were present in most somatic $(N$ $=44)$ and dendritic $(N=10)$ patches studied, resulting in complex recordings such as those shown in Figures 3 and 4. The majority of this activity was identified as arising from $\mathrm{K}^{+}$channel types based on the reversal potentials for the unitary events.

In these studies, the high- $\mathrm{K}^{+}$saline for the recording electrode 
A

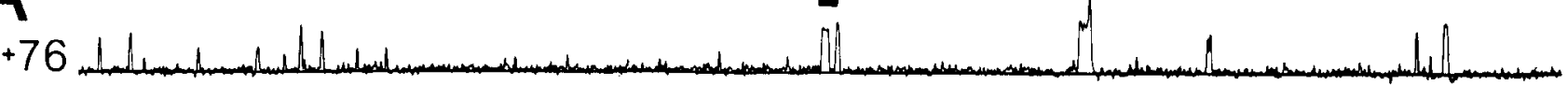
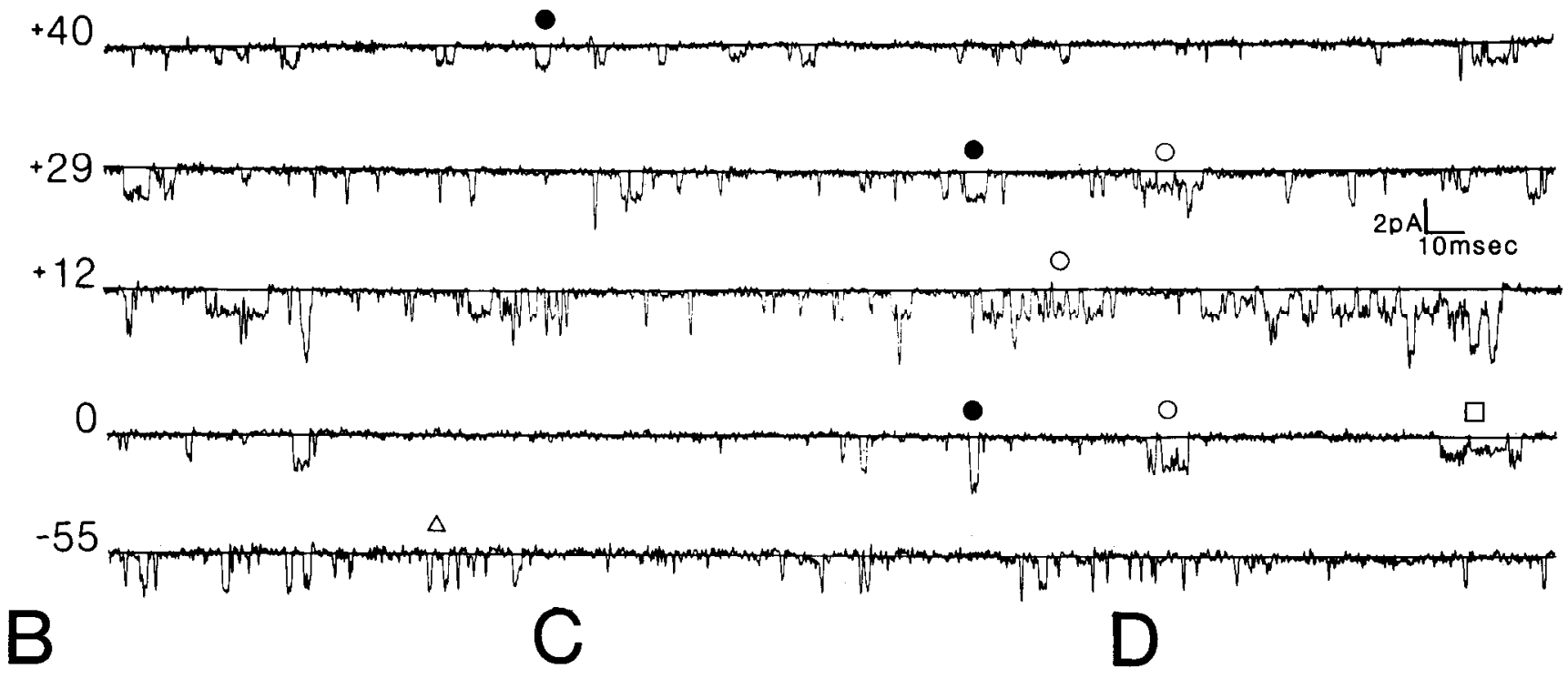

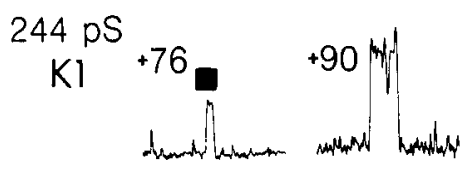

$46 \mathrm{pS}$

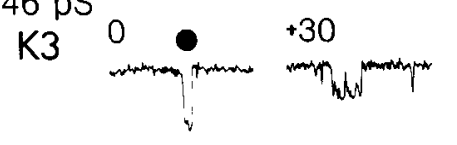

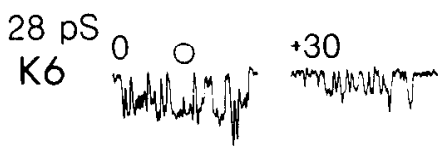

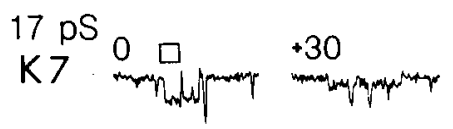

$12 \mathrm{pS}$

K8 $-86 \Delta \Delta \quad-40$
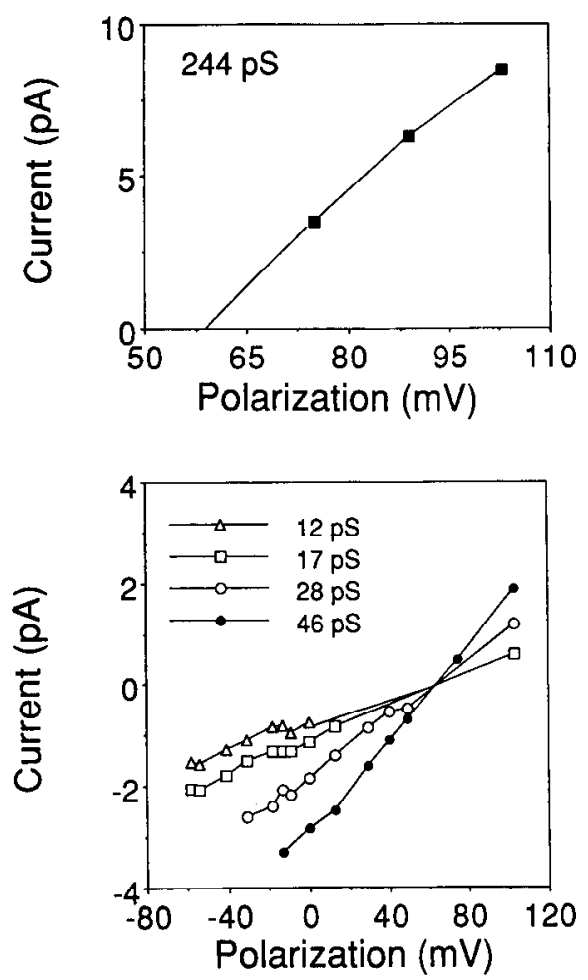
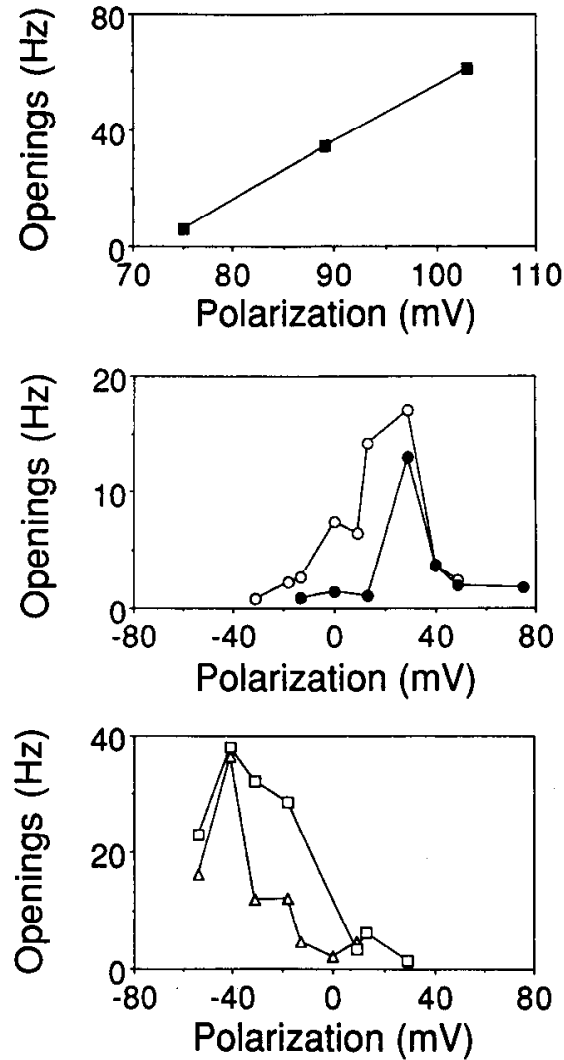

Figure 3. Cell-attached recording showing voltage-sensitive $\mathrm{K}^{+}$channel activity recorded in the somatic region with a high- $\mathrm{K}^{+}$saline (KCl)-filled electrode. $A$, Polygraph recordings show single-channel events and patterns of activity at different membrane potentials. Some channels are labeled with symbols to indicate channel type. Five $\mathrm{K}^{+}$channel types were present in the patch and were identified as the $K 1(\square), K 3(\bullet), K 6(0), K 7(\square)$, and $K 8(\triangle)$ channel types. Selected channel events are shown in $B$ for each channel type. The computer-generated I-V curves are shown in $C$. Slope conductances were $244(\mathrm{~K} 1), 46(\mathrm{~K} 3), 28(\mathrm{~K} 6), 17(\mathrm{~K} 7)$, and $12(\mathrm{~K} 8) \mathrm{pS}$. The reversal potential, at a depolarization of $60 \mathrm{mV}$, is consistent with $\mathrm{K}^{+}$-selective channel types. The effect of membrane polarization on the frequency of channel openings is shown in $D$ for each channel type. For the 46- and 17-pS channel types, the decline in opening frequency at depolarized potentials was accompanied by an increase in the duration of the channel openings. Graphs are constructed from data obtained at polarizations where channel activity was frequent enough and the unitary events large enough for computer quantification. 

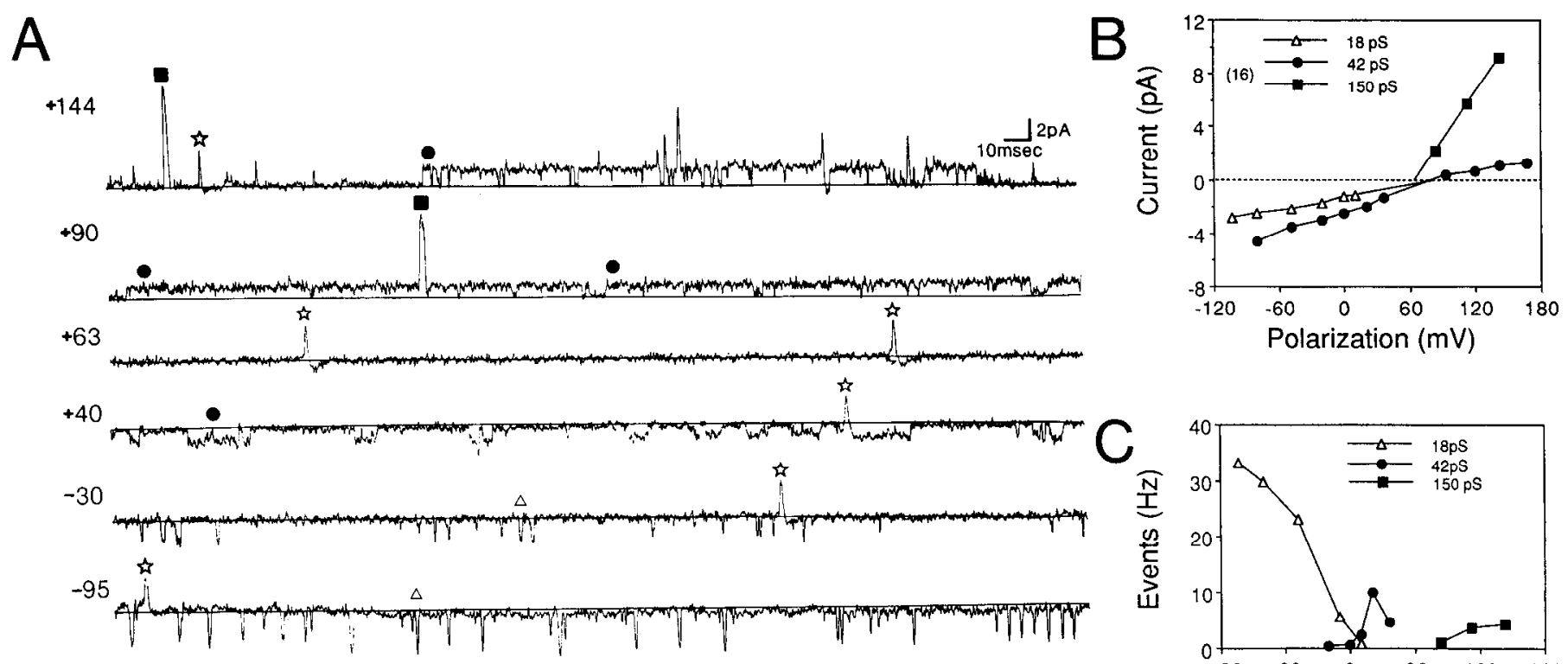

Cell-attached recording showing voltage-sensitive $\mathrm{K}^{+}$channel activity recorded in the dendritic region with a high- $\mathrm{K}^{+}$saline $(\mathrm{KCl})$-filled electrode. In $A$, polygraph recordings show single-channel events and patterns of activity at different membrane potentials. Some channel events are labeled with symbols to indicate channel type. Three $\mathrm{K}^{+}$channel types were present in the patch and were identified as the $\mathrm{K} 1(\square)$, $\mathrm{K} 3(\boldsymbol{O})$, and $\mathrm{K} 8(\triangle)$ channel types. Slope conductances were 150,42 , and $18 \mathrm{pS}$, respectively. Current-voltage relations are shown in $B$. The number in parentheses on the current axis refers to the amplitude of 150 -pS channel type events. The reversal potential was similar for all channel types and consistent with $\mathrm{K}^{+}$-selective channel types under the ionic conditions used. The effect of membrane potential on the frequency of channel openings is shown in $C$ for membrane polarizations where quantification was possible. For the 42-pS channcl typc, the decline in opening frequency at depolarized potentials was accompanied by an increase in the duration of the channel openings. Spontaneous spike events are evident in most traces (some labeled with a star).

was prepared from $\mathrm{K}^{+}$-gluconate or $\mathrm{KCl}$. Studies with $\mathrm{KCl}$-filled electrodes were carried out first, so that $\mathrm{K}^{+}$channel types could be distinguished from $\mathrm{Cl}^{-}$channel types by the reversal potential for the unitary events. The calculated equilibrium potential for $\mathrm{K}^{+}$was approximately $0 \mathrm{mV}$ for both salines (i.e., approximately $60 \mathrm{mV}$ depolarized from rest); the equilibrium potential for $\mathrm{Cl}^{-}$ was approximately $-60 \mathrm{mV}$ (i.e., resting membrane potential) when $\mathrm{KCl}$-filled electrodes were used and approximately $0 \mathrm{mV}$ when $\mathrm{K}^{+}$-gluconate-filled electrodes were used. The reversal potentials for $\mathrm{K}^{+}$channel types were similar under both conditions. Mean values were $60 \pm 2$ depolarized from rest $(N=37)$ for recordings made with $\mathrm{KCl}$-filled electrodes and $59 \pm 2 \mathrm{mV}$ depolarized from rest $(N=13)$ for recordings made with $\mathrm{K}^{+}$gluconate-filled electrodes. $\mathrm{K}^{+}$channel activity and the properties of the $\mathrm{K}^{+}$channel types were similar in recordings made with $\mathrm{KCl}$ - and $\mathrm{K}^{+}$-gluconate-filled electrodes. Chloride-selective channels were observed in some cell-attached patches but were not studied. In 4 cells, both the bath and the recording electrode contained high- $\mathrm{K}^{+}$saline prepared from $\mathrm{KCl}$. Under these conditions, the cell membrane potential was depolarized to $0 \mathrm{mV}$. The estimated equilibrium potentials for $\mathrm{K}^{+}$and $\mathrm{Cl}^{-}$-elective events were 0 and $-63 \mathrm{mV}$, respectively. In these patches, the reversal potential for channel types identified as $\mathrm{K}^{+}$selective based on other characteristics was at resting membrane potential (i.e., $0 \mathrm{mV}$ ), consistent with the identification of the $\mathrm{K}^{+}$channel types as $\mathrm{K}^{+}$selective (data not shown).

Six $\mathrm{K}^{+}$channel types were identified in the cell-attached recordings under symmetrical $\mathrm{K}^{+}$conditions, based on singlechannel conductance, reversal potential, voltage sensitivity, and patterns of activity. A mean of $3.5 \pm 0.2$ channels and a mean of $2.8 \pm 0.2$ different channel types were observed per patch $(N$ $=54$ ). The properties of these channel types are illustrated in Figures 3-6. All 6 channel types were present in both the somatic and the dendritic membranes. Mean slope conductances measured in the linear range of the I-V relations were $222,134,39$, 25,14 , and $15 \mathrm{pS}$ (Table 1). The most commonly observed channel types were the 222-, 39-, and 25-pS channel types. As shown in Figure 5, the 222- and 39-pS channel types exhibited patterns of activity, open channel properties, and voltage sensitivity similar to that observed for the $\mathrm{K} 1$ and $\mathrm{K} 3$ channel types characterized in cell-attached patches under physiological conditions. Thus, the 222-pS channel type and K1 (93 pS) channel type both required strong depolarizations $(>60 \mathrm{mV})$ for activation; the frequency of openings and the duration of the open state increased as a function of membrane depolarization. Similarly, the 39-pS channel type and the K3 (12-pS) channel type were both activated by small depolarizations where infrequent clusters of openings were observed; prolonged openings were elicited by strong depolarizations. IIowever, the single-channel conductance for both channel types were approximately 2-3 times larger under the symmetrical $\mathrm{K}^{+}$conditions.

A third channel type observed under symmetrical $\mathrm{K}^{+}$conditions, the 134-pS channel type, also exhibited properties similar to a channel type observed in cell-attached recordings under physiological conditions, the K2 channel type. The 134-pS channel type and the $\mathrm{K} 2$ channel type were both characterized by a low frequency of detection in cell-attached recordings, maximal activity at membrane potentials ranging from 30 to $60 \mathrm{mV}$ depolarized from rest, and long-duration openings at potentials where maximal activity was observed (data not shown). As for 
A
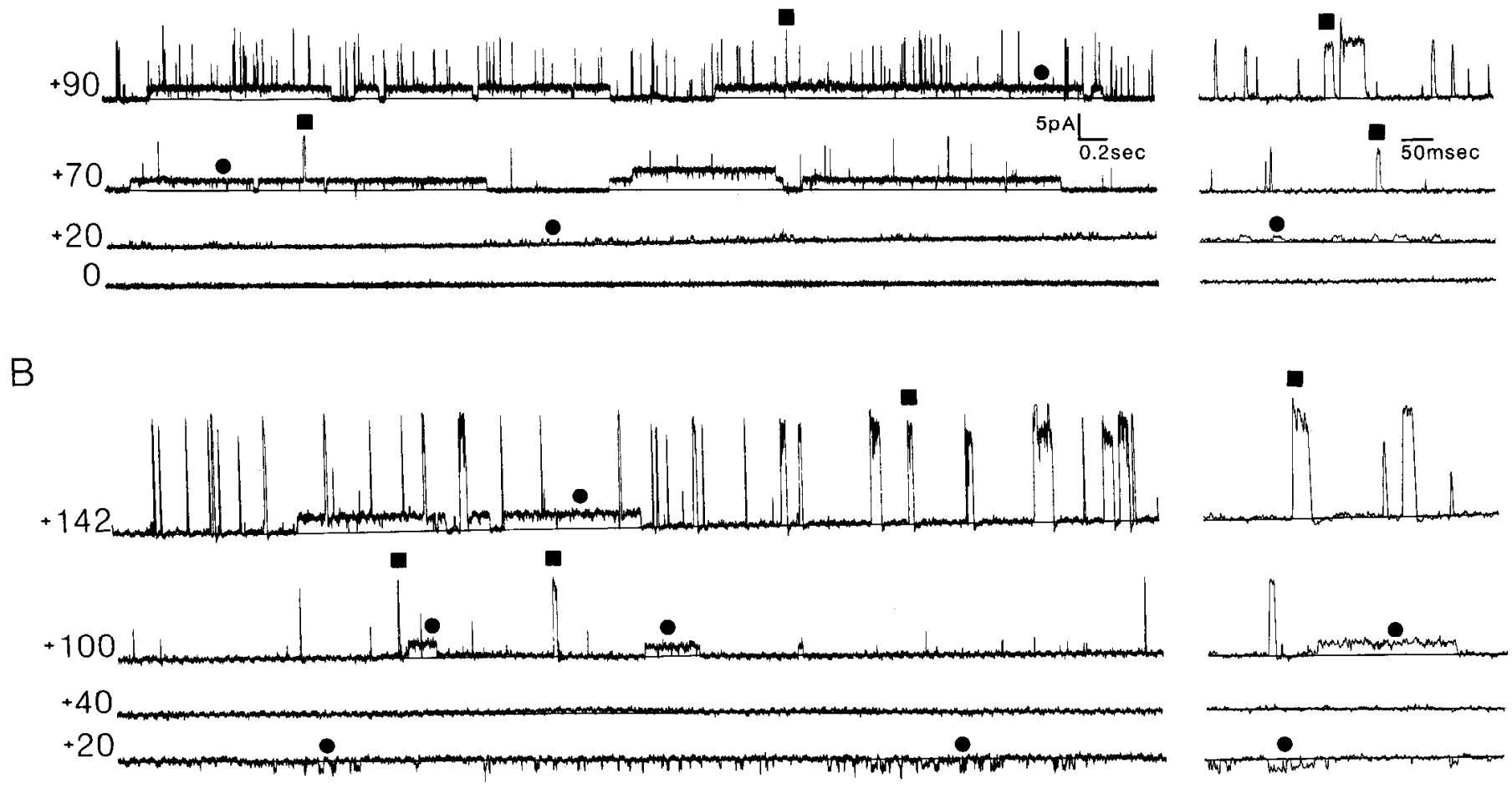

Figure 5. Cell-attached somatic recordings from 2 neurons showing the activity of the $\mathrm{K} 1$ and $\mathrm{K} 3$ channel types under 2 ionic conditions. The recording clcctrode containcd physiological saline in $A$ and high- $\mathrm{K}^{+}$saline ( $\mathrm{K}^{+}$-gluconate) in $B$. The single-channel activity is shown at 2 time bases. Similar outward current events mediated by a large ( $(\boldsymbol{)})$ and small $(\bullet)$ channel type were evoked by depolarizing voltage commands under both ionic conditions. Single-channel conductances were $13 \mathrm{pS}(\mathrm{K} 3)$ and $90 \mathrm{pS}(\mathrm{K} 1)$ for the 2 channel types in $A$ and $38 \mathrm{pS}(\mathrm{K} 3)$ and $250 \mathrm{pS}(\mathrm{K} 1)$ for the 2 channel types in $B$. The extrapolated reversal potential was $\sim 25 \mathrm{mV}$ hyperpolarized from rest for both channel types under physiological ionic conditions and $\sim 60 \mathrm{mV}$ depolarized from rest for the high- $\mathrm{K}^{+}$-filled electrodes. These values are consistent with the expected reversal potential for $\mathrm{K}^{+}$channel types under the respective ionic conditions.

the $\mathrm{K} 1$ and $\mathrm{K} 3$ channel types, single-channel conductance was larger under the symmetrical $\mathrm{K}^{+}$conditions. Based on these similarities, the 222-, 134-, and 39-pS channel types observed in cell-attached patches under symmetrical $\mathrm{K}^{+}$conditions are considered to correspond to the $\mathrm{K} 1, \mathrm{~K} 2$, and $\mathrm{K} 3$ channel types, respectively, observed in cell-attached recordings under physiological conditions.

The smaller-conductance channel types identified in cell-attached recordings under symmetrical $\mathrm{K}^{+}$conditions, with mean conductances of 25,14 , and $15 \mathrm{pS}$, did not exhibit properties similar to channel types observed in cell-attached recordings under physiological conditions. These 3 channel types were active at resting membrane potential, in contrast to the $\mathrm{K} 1, \mathrm{~K} 2$, and $\mathrm{K} 3$ channel types, which required membrane depolarization for activation. However, the activity of the channels varied with membrane potential, indicating that they are also voltage-sensitive channel types. These channel types will be referred to as the K6 (25-pS), K7 (14-pS), and K8 (15-pS) channel types. Of these, the K6 channel type was the most frequently observed (Table 1).

The K6 (25-pS) channel type contributed prominently to channel activity at resting potential and at potentials around rest (polarizations ranging from -20 to $+30 \mathrm{mV}$ ). Openings occurred in clusters of unitary events (Figs. 3,6 ). This channel type showed the most inactivation of the 6 channel types observed under symmetrical $\mathrm{K}^{+}$conditions, responding to membrane depolarizations with an intense burst of activity followed by infrequent clusters of openings. Activity due to this channel type was not observed at strong depolarizations (Fig. 6).

The K7 (14-pS) channel type was also active at resting membrane potential, where long-duration openings or clusters of openings similar to opcnings of the $\mathrm{K} 6$ channel type were observed (Fig. 3). However, this channel type did not show the prominent inactivation characteristic of the $\mathrm{K} 6$ channel type and was active over a wider range of membrane potentials. This channel type could be most easily identified at potentials ranging from -30 to $+80 \mathrm{mV}$ from rest, where small-amplitude, longduration openings were observed. Single, short-duration openings occurred at more hyperpolarized potentials.

The third channel active at rest, the K8 (15-pS) channel type, differed from the $\mathrm{K} 6$ and $\mathrm{K} 7$ channel types in that channel activity was characterized by short-duration, single openings at all potentials where activity was observed and in that maximal activity occurred at hyperpolarized membrane potentials (Figs. $3,4)$. Openings for this channel type were not observed when the membrane was depolarized more than $20 \mathrm{mV}$ from rest.

Association of $K^{+}$channel activity with physiological responses. Spontancous spike events were often observed in cell-attached somatic and dendritic recordings. These spike events resembled the single-unit activity that is recorded from CNS neurons in vivo using extracellular recording techniques. When high- $\mathrm{K}^{+}$saline was used in the recording electrode, $\mathrm{K}^{+}$channel activity was associated with the extracellularly recorded spike events, suggesting a functional role for the $\mathrm{K}^{+}$channel types in the 
A type associated with spike events in a cell-attached somatic recording. The recording electrode contained high- $\mathrm{K}^{+}$saline. The spike events are shown at a slow time base in $A$ and a fast time base in $B$. Single-channel conductance was $28 \mathrm{pS}$, determined from the I-V curve. The I-V curve was constructed from the amplitude of the unitary events at the end of the spike event where the membrane potential was close to resting value. Infrequent channel events of the same type also occurred during interspike intervals at test potential where the channel events were associated with spikes and yielded a similar slope conductance value. At command potentials greater than +20 $\mathrm{mV}$, the channel activity was not evident or showed rapid inactivation following the onset of the command step. A depolarization of $60 \mathrm{mV}$ represented the extrapolated null potential for $\mathrm{K}^{+}$selective channels in this patch.

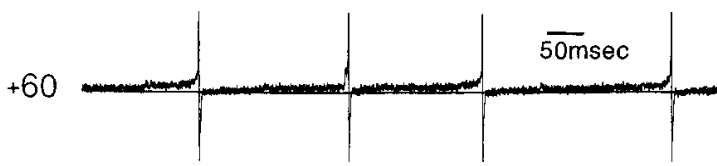

$+40$
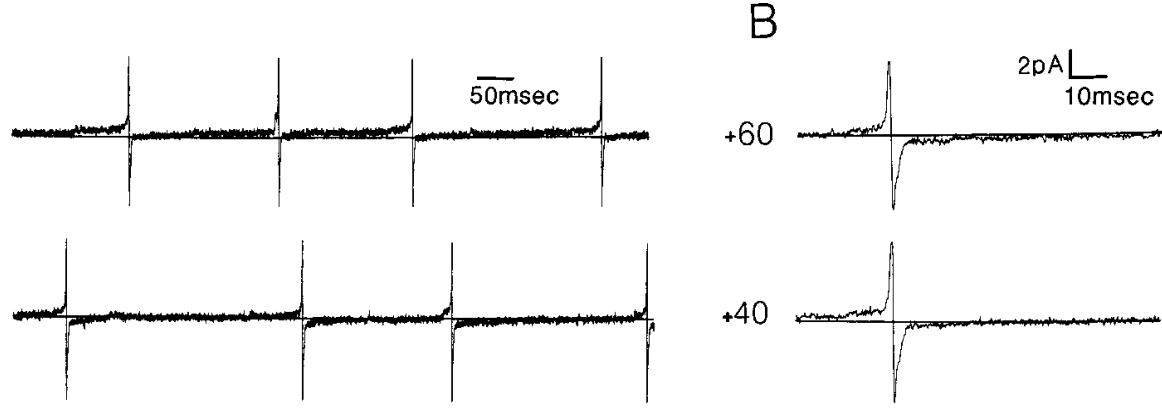

$+10$
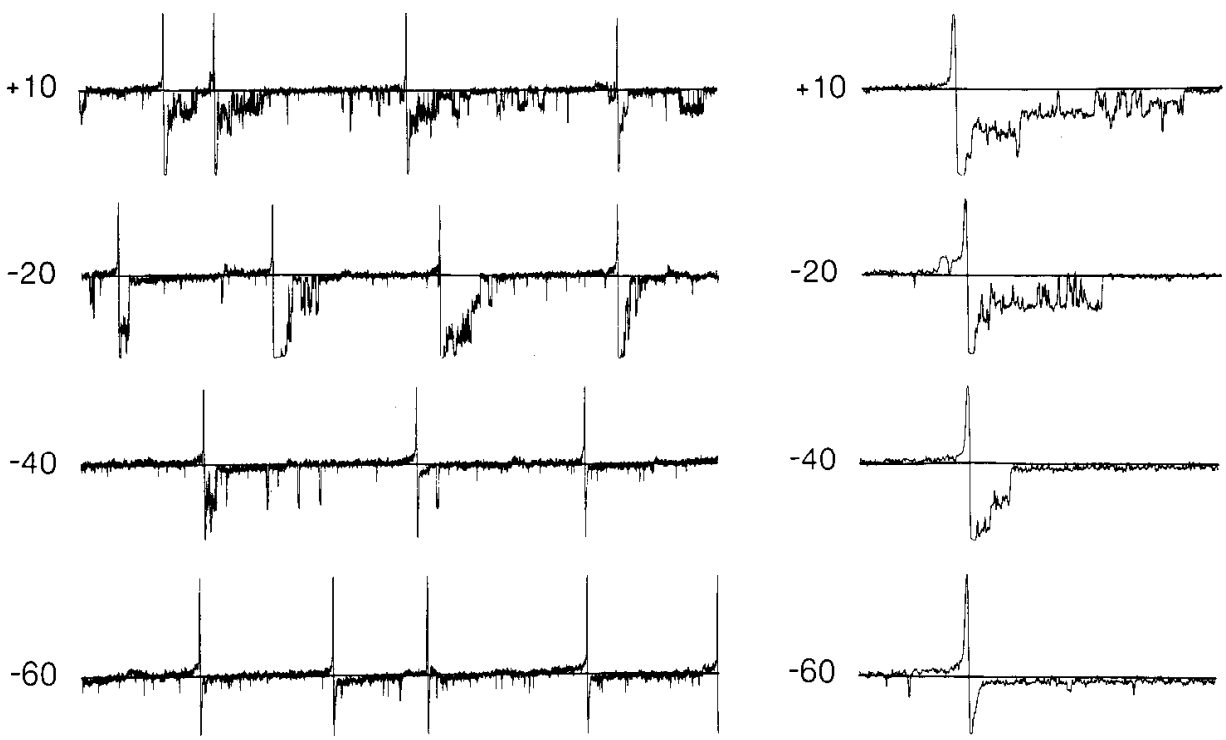

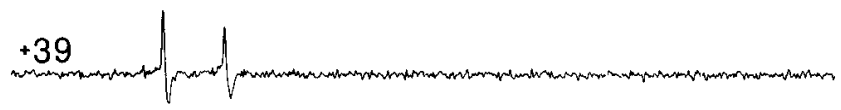

b

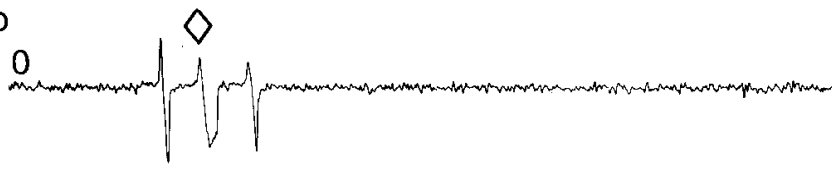

C

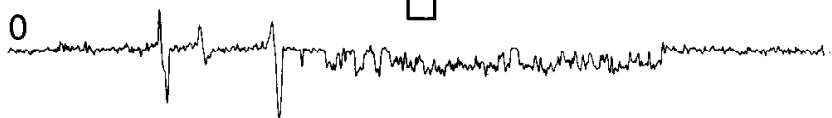

d

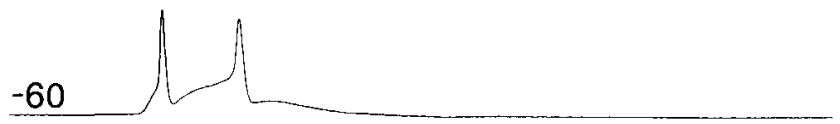

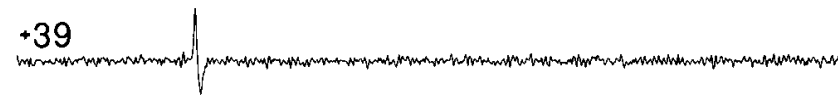

f

0

$2 \mathrm{pAl}$

g

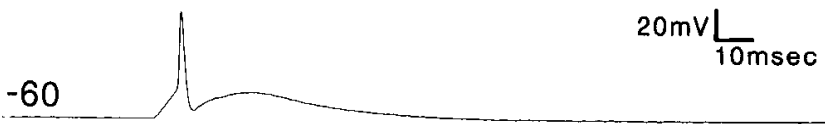

h

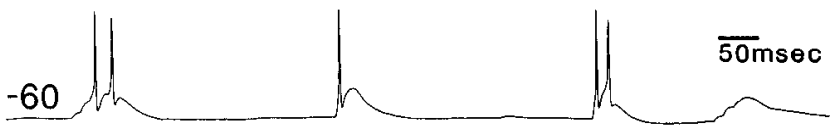

Figure 7. Single-channel activity associated with spike events in a cell-attached dendritic recording. The recording electrode contained high-K ${ }^{+}$ saline. Channel activity is shown at resting membrane potential $(0$ applied polarization; $b, c$, and $f)$ and at a potential where no channel activity was observed (39 mV applied depolarization; $a$ and $e$ ). Single-channel conductances were $16 \mathrm{pS}(\square)$, $35 \mathrm{pS}(\mathbf{\odot})$, and $100 \mathrm{pS}(\diamond)$. The $16-\mathrm{pS}$ and 35 -pS channels were classified as K7 and K3 channel types; the activity of the 100-pS channel was too infrequent for sufficient analysis. Subsequent intracellular recordings are shown in $d, g$, and $h$. Spontaneous synaptic potentials and synaptically driven singlet and doublet spikes were observed in the intracellular recordings. A comparison of the extracellular and intracellular recordings indicates that the channel events occurred during the repolarizing phase of spike events and synaptic potentials. 
A
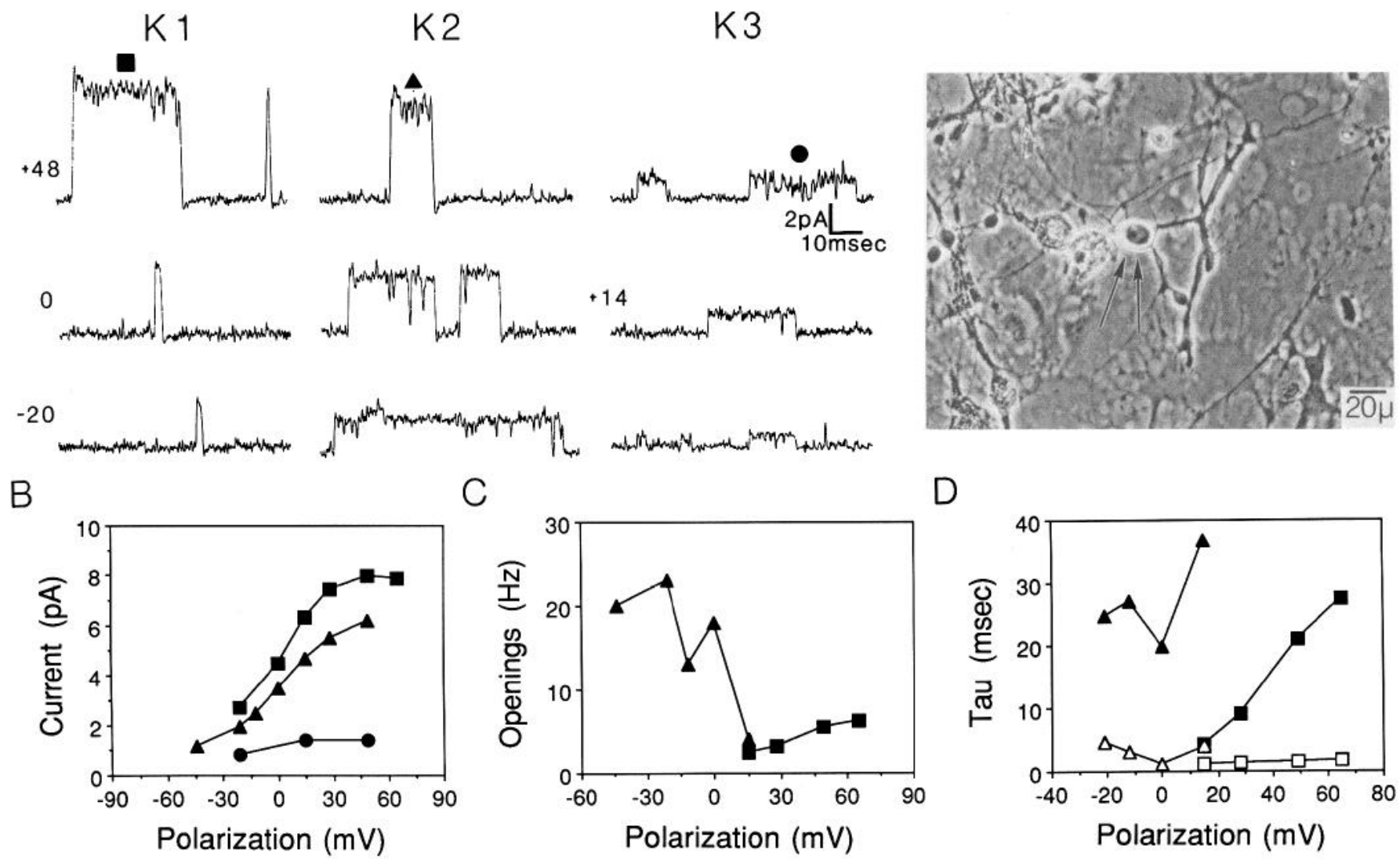

Figure 8. Voltage-sensitive $\mathrm{K}^{+}$channel activity of the $\mathrm{K} 1, \mathrm{~K} 2$, and $\mathrm{K} 3$ channel types recorded in an outside-out dendritic patch. The recording electrode contained high- $\mathrm{K}^{+}$saline. A phase-contrast micrograph of the recorded neuron (at the tip of the arrows) is shown at the upper right. Single-channel conductances, derived from the slope of the I-V curve in the range of -30 to $+30 \mathrm{mV}$, were $97(K 1 ; \mathbf{\square}), 75(K 2 ; \mathbf{\Delta})$, and $18(K 3$; -) pS. Sample polygraph recordings of channel activity at different membrane potentials are shown in $A$. I-V curves are shown in $B$. The effect of membrane potential on the frequency of channel openings $(\mathrm{Hz})$ is shown in $C$ for the $\mathrm{K} 1$ and $\mathrm{K} 2$ channel types. Mean open times $(\tau$ values) are shown in $D$. The open-time histogram for both channel types required 2 exponentials (represented as open and solid symbols) to fit the data. Only unitary events were used for construction of open-time histograms. Mean open times were derived from exponential fits of the open-time histograms using a maximum likelihood estimation.

generation of somatic and dendritic action potentials (Figs. 6, 7). A correlation of extracellular and intracellular recordings from the same neuron indicated that the $\mathrm{K}^{+}$channels were activated during the repolarizing phase of the action potentials and synaptic events (Fig. 7). At resting membrane potential (i.e., no applied polarization), $2 \mathrm{~K}^{+}$channel types were commonly associated with the extracellularly recorded spike events, the K3 (39-pS) and K6 (25-pS) channel types. Larger-conductance $\mathrm{K}^{+}$ channel types were associated with spike events in some recordings, but could not be unequivocally identified due to the short duration of the unitary events.

Channel activity in outside-out patches. The cell-attached recording configuration enables a study of membrane ion channels under physiological conditions. However, experimental manipulations available with this technique are rather limited. Thus, we initiated a study of outside-out patches to determine if the voltage-sensitive $\mathrm{K}^{+}$channel types identified in cell-attached patches could be identified in outside-out patches. Fifty-two somatic and 7 dendritic patches were studied. As for cell-attached patches studied under physiological conditions, channel activity was infrequent at the normal resting potential of the Purkinje neuron, approximately $-60 \mathrm{mV}$, and at more hyper- polarized potentials. Depolarization of the membrane evoked outward current events of several amplitudes. These current events were identified as arising from the activity of 5 voltagesensitive $\mathrm{K}^{+}$channel types, based on single-channel conductance, reversal potential, voltage sensitivity, patterns of activity, and the relative duration of the open state. All $5 \mathrm{~K}^{+}$channel types were present in the somatic and dendritic regions. Mean slope conductances measured in the linear range of the depolarizing I-V relation were $93,73,41,26$, and $16 \mathrm{pS}$ (Table 1). A clear reversal of the outward current events at potentials hyperpolarized to $-60 \mathrm{mV}$ was not observed for any of the $\mathrm{K}^{+}$ channel types.

In these studies, the recording electrodes contained high- $\mathrm{K}^{+}$ saline prepared from either $\mathrm{KCl}$ or $\mathrm{K}^{+}$-gluconate. The bath contained physiological saline. Studies with the $\mathrm{KCl}$ saline were carried out first so that $\mathrm{K}^{+}$channel types could be distinguished from $\mathrm{Cl}^{-}$channel types based on the reversal potential for the unitary events. The mean extrapolated reversal potential for the $\mathrm{K}^{+}$channel types was $-63 \pm 2 \mathrm{mV}(N=45)$ when $\mathrm{KCl}$-filled electrodes were used and $-62 \pm 4 \mathrm{mV}(N=12)$ when $\mathrm{K}^{+}-$ gluconate-filled electrodes were used. The calculated equilibrium potential for $\mathrm{K}^{+}$was $-95 \mathrm{mV}$ under both recording con- 
ditions; the calculated equilibrium potential for $\mathrm{Cl}^{-}$was $3 \mathrm{mV}$ for $\mathrm{KCl}$-filled electrodes and $-73 \mathrm{mV}$ for $\mathrm{K}^{+}$-gluconate-filled electrodes. Characteristics of $\mathrm{K}^{+}$channel activity such as voltage sensitivity and pattern of activity were similar in recordings made with $\mathrm{KCl}$ - and $\mathrm{K}^{+}$-gluconate-filled electrodes.

In the outside-out patches, the most commonly observed $\mathrm{K}^{+}$ channel types were the 93-, 73-, and 16-pS channel types. The characteristics of these channel types are illustrated in Figure 8, obtained from a dendritic patch that contained all 3 channel types. These channel types exhibited properties similar to the K1 (92-pS), K2 (57-pS), and K3 (12-pS) channel types, respectively, observed in cell-attached recordings under physiological conditions. Thus, the $\mathrm{K} 1$ channel type in cell-attached recordings and the 93-pS channel type in outside-out patches were most active at strong depolarizations (i.e., at membrane potentials $>+20 \mathrm{mV}$ ); the frequency of openings and the duration of the open state increased as a function of membrane depolarization. Similarly, the K2 channel type in cell-attached patches and the 73-pS channel type in outside-out patches were most active at moderate depolarizations where long-duration openings were observed. $\Lambda \mathrm{t}$ strong depolarizations, the frequency of activity and the duration of the open state decreased. However, the $\mathrm{K} 2$ channel type was a common feature of outside-out patches, but was observed only infrequently in cell-attached patches (Table 1). The K3 channel type in cell-attached patches and the 16-pS channel type in outside-out patches both exhibited smallamplitude, prolonged openings at strong depolarizations and infrequent short-duration openings at small depolarizations. Based on these similarities, the 93-, 73-, and 16-pS channel types observed in outside-out patches are considered to correspond to the $\mathrm{K} 1, \mathrm{~K} 2$, and $\mathrm{K} 3$ channel types identified in cellattached recordings.

The high activity of the $\mathrm{K} 1, \mathrm{~K} 2$, and $\mathrm{K} 3$ channel types in outside-out patches limited the characterization of the 2 other $\mathrm{K}^{+}$channel types, the 41- and 26-pS channel types, observed in this recording configuration. However, both channel types appeared to be most active at strong membrane depolarizations. The 26-pS channel exhibited bursting behavior, while the 41pS channel was characterized by prolong openings (data not shown). These 2 channel types will be referred to as the K4 (41$\mathrm{pS}$ ) and $\mathrm{K} 5$ (26-pS) channel types. The K1, K2, K4, and K5 channel types observed in the current study appear to be the same channel types as observed previously in outside-out somatic patches studied under different ionic conditions with mean conductances of 100, 70, 44, and $27 \mathrm{pS}$, respectively (Yool et al., 1988)

$\mathrm{K}^{+}$channel types were a prominent component of outsideout patches from both the somatic and the dendritic membrane. All patches contained voltage-sensitive $\mathrm{K}^{+}$channel types, with a mean of $3.4 \pm 0.2$ total channels and $1.7 \pm 0.1$ different channel types per patch $(N=59)$.

Effect of external $K^{+}$on single-channel conductance. As outlined above, the properties of the K1, K2, and K3 channel types identified in cell-attached patches under physiological conditions were similar to the properties of channel types studied in outside-out recordings under physiological conditions and cellattached recordings under symmetrical $\mathrm{K}^{+}$conditions. This similarity led to a correlation of the channel types under the different recording conditions. However, the single-channel conductance of all 3 channel types was 2-3 times larger under the symmetrical $\mathrm{K}^{+}$conditions. To determine if this difference was due to the high extracellular $\mathrm{K}^{+}$, these channel types were studied in out- side-out patches first under physiological conditions and then under symmetrical $\mathrm{K}^{+}$conditions. The conductance of all 3 channel types was found to increase approximately $2-3$ times when the external physiological saline was replaced with high$\mathrm{K}^{+}$saline. Mean conductance values were $95 \pm 4 \mathrm{pS}$ and 227 $\pm 9(N=8)$ for the $\mathrm{K} 1$ channel type, $69 \mathrm{pS}$ and $150 \mathrm{pS}$ for the $\mathrm{K} 2$ channel type $(N=1)$, and $18 \pm 3 \mathrm{pS}$ and $42 \pm 5 \mathrm{pS}(N=$ 4) for the $\mathrm{K} 3$ channel type under physiological and then symmetrical $\mathrm{K}^{+}$conditions, respectively.

\section{Discussion}

Using the single-channel recording technique, we have shown that multiple voltage-sensitive $\mathrm{K}^{+}$channel types are present in the somatic and dendritic membranes of cerebellar Purkinje neurons in culture. All patches studied contained voltage-sensitive $\mathrm{K}^{+}$channels and usually multiple channels of the same and different types. The prominent nature of $\mathrm{K}^{+}$channels in these recordings indicates that $\mathrm{K}^{+}$channel types are a major functional component of the somatic and dendritic membranes of the Purkinje neuron.

The $\mathrm{K}^{+}$channel types were studied in the cell-attached, insideout, and outside-out recording configurations. Physiological and symmetrical $\mathrm{K}^{+}$conditions were used. The largest number of $\mathrm{K}^{+}$channel types was identified in cell-attached recordings under symmetrical $\mathrm{K}^{+}$conditions, where the single-channel conductance was enhanced and channel activity could be detected over a wide range of membrane potentials. Six $\mathrm{K}^{+}$channel types were identified. Three of these channel types, referred to as the K1, $\mathrm{K} 2$, and $\mathrm{K} 3$ channel types, exhibited properties similar to channel types identified in cell-attached and outside-out patches under physiological conditions. The single-channel conductance was 2-3 times larger under the symmetrical $\mathrm{K}^{+}$conditions, as has been reported previously for $\mathrm{K}^{+}$channel types studied in other preparations (see below). Correlated channel types showed similar voltage sensitivity and patterns of activity under the different recording conditions. However, one channel type, the $\mathrm{K} 2$ channel type, showed high activity in outside-out patches but only infrequent activity in cell-attached patches. This difference may be due to the absence in outside-out patches of intracellular factors that normally regulate channel activity.

The smaller-conductance $\mathrm{K}^{+}$channel types (K6, K7, and $\mathrm{K} 8$ ) observed in cell-attached patches under symmetrical $\mathrm{K}^{+}$conditions did not correlate with channel types observed in patches studied under physiological conditions. However, the conductance of these channel types may have been 2-3 times smaller under physiological conditions, as was observed for $K 1, K 2$, and K3 and channel types. In this case, the small amplitude of the unitary events at potentials where maximal activity was observed may have prevented detection. Two channel types observed in outside-out patches ( $\mathrm{K} 4$ and $\mathrm{K} 5$ ) were also not correlated with channel types observed in cell-attached patches under physiological or symmetrical $\mathrm{K}^{+}$conditions. This difference may also be due to the absence in outside-out patches of intracellular factors that normally regulate channel activity, as was proposed for the $\mathrm{K} 2$ channel type.

The presence of multiple channel types in most patches and the inability to selectively isolate individual channel types for study prevented a detailed analysis of kinetic properties and a more rigorous study of voltage sensitivity of the $\mathrm{K}^{+}$channel types. Without this information, an unequivocal correlation of the $\mathrm{K}^{+}$channel types with known $\mathrm{K}^{+}$conductances is not possible. However, a comparison of the properties of channel types 
observed in these studies with channel types characterized in other preparations has permitted a tentative identification of some channel types. Based on intracellular and voltage-clamp studies, Purkinje neurons are expected to express a delayedrectifier, A-current, anomalous rectifier and a $\mathrm{Ca}^{2+}$-activated $\mathrm{K}^{+}$ conductance (Llinas and Sugimori, 1980a,b; Crepel and PenitSoria, 1986; Bossu et al., 1988; Gahwiler and Llano, 1989). Singlc-channel studies in several cell types have revealed $\mathrm{K}^{+}$ channel types that exhibit properties expected for these classes of $\mathrm{K}^{+}$conductances. The properties appear to vary according to cell type.

Delayed-rectifier channels are characterized by single-channel conductances ranging from $\sim 7$ to $30 \mathrm{pS}$ under physiological conditions and from $\sim 30$ to $35 \mathrm{pS}$ under symmetrical $\mathrm{K}^{+}$conditions, depending on cell type (Conti and Neher, 1980; Ypey and Clapham, 1984; Cahalan et al., 1985; Standen et al., 1985; Rogawski, 1986; Harris et al., 1988; Hoshi and Aldrich, 1988; Quandt, 1988). In the present study, the channel type designated as $\mathrm{K} 3$ exhibited characteristics typical for a delayed-rectifier channel. These characteristics include activation by membrane depolarization and the absence of pronounced inactivation. The mean single-channel conductance of the $\mathrm{K} 3$ channel type was $16 \mathrm{pS}$ under physiological conditions and $39 \mathrm{pS}$ under symmetrical $\mathrm{K}^{+}$conditions, consistent with values obtained for delayed-rectifier channels in other cell types under these ionic conditions. The association of this channel type with the repolarizing phase of spontaneous actions potentials is consistent with the proposal that is a delayed-rectifier channel type, a channel type known to function in action potential repolarization. This channel type appears to be similar to a 22-pS channel identified by Bussu et al. (1988) in Purkinje neurons maintained under different culture conditions.

Rapidly inactivating $\mathrm{K}^{+}$channels that exhibit voltage sensitivity typical of A-currents are characterized by single-channel conductances ranging from $\sim 5$ to $22 \mathrm{pS}$ under physiological conditions, depending on cell type (Kasai et al., 1986; Solc et al., 1987; Taylor, 1987; Hoshi and Aldrich, 1988). In the present study, only 1 channel type, the K6 channel type, showed prominent inactivation when depolarizing commands were applied from a hyperpolarized holding potcntial, a charactcristic expected for an A-channel type. The single-channel conductance of this channel type was $25 \mathrm{pS}$ under symmetrical $\mathrm{K}^{+}$conditions. Assuming either the same conductance in physiological saline or a conductance value 2-3 times smaller, as was found for the $\mathrm{K} 1, \mathrm{~K} 2$, and $\mathrm{K} 3$ channel types, this channel type would fit in the range of conductances previously reported for A-channel lypes under physiological conditions. The association of this channel type with the repolarizing phase of spontaneous actions potentials is consistent with the proposal that it may be an A-channel type. Intracellular studies have shown that A-currents function in the repolarization of action potentials in other CNS neurons (Storm, 1987).

In the present study, only 1 channel type, designated as K8, showed high activity restricted to hyperpolarized membrane potentials. Activity at hyperpolarized potentials would be expected for an anomalous rectifier channel. The mean singlechannel conductance under symmetrical $\mathrm{K}^{+}$conditions was 15 $\mathrm{pS}$, within the range $(\sim 10-40 \mathrm{pS})$ reported for anomalous rectifier channels in other cell types (Ohmori et al., 1981; Sakmann and Trube, 1984; Burnashev and Zilberter, 1986; Josephson and Brown, 1986; Shingai and Quandt, 1986; Matsuda et al., 1987).
Two large-conductance channel types, designated as $\mathrm{K} 1$ and $\mathrm{K} 2$, were also observed in the current study. The $\mathrm{K} 1$ channel type exhibited properties similar to the BK channel, a largeconductance, $\mathrm{Ca}^{2+}$-activated $\mathrm{K}^{+}$channel first characterized in muscle (Palotta et al., 1981; Barrett et al., 1982) and chromaffin cells (Marty, 1981) and later found to be common to many cell types. The BK channel is activated by membrane depolarization, has a large conductance that varies with the extracellular $\mathrm{K}^{+}$level, and exhibits high sensitivity to $1 \mathrm{~mm}$ external tetraethylammonium (TFA). In the present study, the K1 channel type was activated by membrane depolarization and exhibited conductance values similar to the BK channel under physiological and symmetrical $\mathrm{K}^{+}$conditions. We have previously shown that external TEA at a 1 mM concentration antagonizes the activity of this channel type (Yool et al., 1988). Additional studies in progress have shown that the activity of this channel type is dependent on the level of internal $\mathrm{Ca}^{2+}$ (Gruol and Jacquin, 1989). These properties suggest that $\mathrm{K} 1$ channel type is the BK channel. Recently, Gahwiler and Llano (1989) have described a similar $\mathrm{K}^{+}$channel type in outside-out somatic patches from Purkinje neurons maintained under different culture conditions. They have also concluded that it is the BK channel type.

The K2 channel type also exhibited a large single-channel conductance that varied with external $\mathrm{K}^{+}$concentration. However, the voltage range for maximal activity of the $K 2$ channel type differed from that of the BK channel type. In the outsideout patches, where the $\mathrm{K} 2$ channel type was commonly detected, maximal activity occurred at small depolarizations. The K1 channel type (i.e., BK channel type) showed little activity at these potentials. At stronger depolarizations, where the $\mathrm{K} 1$ channel type exhibited maximal activity, the activity of the $\mathrm{K} 2$ channel type decreases as a function of membrane potential. We have previously shown that the activity of this channel type is also sensitive to $1 \mathrm{~mm}$ TEA (Yool et al., 1988). In studies in progress, frequency of detecting the $\mathrm{K} 2$ channel type in outsideout patches was found to vary with the internal $\mathrm{Ca}^{2+}$ level, indicating that the activity of this channel type is also regulated by internal $\mathrm{Ca}^{2+}$ (Gruol and Jacquin, 1989). This channel type may correlate with one of the multiple $\mathrm{Ca}^{2+}$-activated $\mathrm{K}^{+}$channel types identified in rat brain membranes studied in lipid bilayers (Farley and Rudy, 1988; Reinhart et al., 1989).

The current demonstration of voltage-sensitive $\mathrm{K}^{+}$channel types in both the somatic and the dendritic membranes of the Purkinje neuron provides direct experimental support for the proposal that active conductances contribute to the membrane functions of both cellular regions in this neuronal type (Llinas, 1975; Llinas and Sugimori, 1980b; Gruol, 1986; Ross and Werman, 1987; Tank et al., 1988; Hockberger et al., 1989). These results compliment the recent single-channel studies of Bossu et al. (1989b) demonstrating that voltage-sensitive $\mathrm{Ca}^{2+}$ channel types are present in the dendritic region of Purkinje neurons in culture. The association of $\mathrm{K}^{+}$channel events with synaptically evoked somatic and dendritic spikes in the current study suggests that one functional role for the voltage-sensitive $\mathrm{K}^{+}$channels is in the repolarization of spikc cvents. Multiple $\mathrm{K}^{+}$channel types were associated with the spike events, consistent with intracellular recordings in other CNS neuronal types showing that multiple $\mathrm{K}^{+}$conductances contribute to spike repolarization (Storm, 1987).

In addition to spike repolarization, the voltage-sensitive $\mathrm{K}^{+}$ channels could also contribute to other important somatic and 
dendritic functions. In cell-attached recordings under symmetrical $\mathrm{K}^{+}$conditions, several $\mathrm{K}^{+}$channel types were active at resting membrane potential, including the $\mathrm{K} 6, \mathrm{~K} 7$, and $\mathrm{K} 8 \mathrm{chan}$ nel types. These channel types may contribute to membrane functions such as establishing the resting membrane potential and generating pacemaker activity. Dendritic $\mathrm{K}^{+}$channel types may also be directly involved in the transduction of synaptic signals. Pharmacological studies have shown that several CNS transmitters regulate the activity of voltage-sensitive $\mathrm{K}^{+}$conductances in neuronal cells (Bloom, 1988). These transmitters include norepinephrine and serotonin, which are present in afferent pathways to the Purkinje neuron in vivo. The current demonstration of voltage-sensitive $\mathrm{K}^{+}$channels in the dendritic region of the Purkinje neuron opens to question whether 1 or more of these channel types are sites of transmitter action at dendritic synapses. Future studies in this area will be important for a more complete understanding of the roles played by dendritic conductances in the transduction and integration of the synaptic signals elicited by different afferent pathways and transmitter types.

\section{References}

Barrett JN, Magleby KL, Pallotta BS (1982) Properties of single calcium-activated potassium channels in cultured rat muscle. J Physiol (Lond) 331:211-230.

Bloom FE (1988) Neurotransmitters: past, present, and future directions. FASEB J 2:32-41.

Bossu J-L, Dupont J-L, Feltz A (1988) Potassium currents in rat cerebellar Purkinje neurones maintained in culture in L15 (Leibovitz) medium. Neurosci Lett 89:55-62.

Bossu J-L, Dupont J-L, Feltz A (1989a) Calcium currents in rat cerebellar Purkinje cells maintained in culture. Neuroscience 30:605619.

Bossu J-L, Fagni L, Feltz A (1989b) Voltage-activated calcium channels in rat Purkinje cells maintained in culture. Pfluegers Arch 414: 92-94.

Burnashev NA, Zilberter YI (1986) Two types of single inward rectifying potassium channels in rat myocardial cells. Gen Physiol Biophys 5:495-504.

Cahalan MD, Chandy KG, DeCoursey TE, Gupta S (1985) A voltagegated potassium channel in human lymphocytes. J Physiol (Lond) 358:197-237.

Conti F, Neher E (1980) Single channel recordings of $\mathrm{K}^{+}$currents in squid axons. Nature 285:140-143.

Crepel F, Penit-Soria J (1986) Inward rectification and low threshold calcium conductance in rat cerebellar Purkinje cells. An in vitro study. J Physiol (Lond) 372:1-23.

Eccles JC, Ito M, Szentagothai J (1967) The cerebellum as a neuronal machine. New York: Springer.

Farley I, Rudy B (1988) Multiple types of voltage-dependent $\mathrm{Ca}^{2+}$ activated $\mathrm{K}^{+}$channels of large conductance in rat brain synaptosomal membranes. Biophys J 53:919-934.

Gahwiler BH, Llano I (1989) Sodium and potassium conductances in somatic membranes of rat Purkinje cells from organotypic cerebellar cultures. J Physiol (Lond) 417:105-122.

Gruol DL (1983) Cultured cerebellar neurons: endogenous and exogenous components of Purkinje cell activity and membrane response to putative transmitters. Brain Res 263:223-241.

Gruol DL (1986) Intracellular analysis of spontaneous and evoked activity in the somatic and dendritic region of Purkinje neurons in culture. Soc Neurosci Abstr 12:1350.

Gruol DL, Crimi CP (1988) Morphological and physiological properties of rat cerebellar neurons in mature and developing cultures. Dev Brain Res 41:135-146.

Groul DL, Franklin CL (1987) Morphological and physiological differentiation of Purkinje neurons in cultures of rat cerebellum. J Neurosci 7:1271-1293.

Gruol DL, Jacquin TJ (1989) Calcium sensitivity of two large con- ductance potassium channels in cerebellar Purkinje neurons. Soc Neurosci Abstr 15:76.

Hamill OP, Marty A, Neher F, Sakmann B, Sigworth FJ (1981) Improved patch clamp technique for high-resolution current recording from cells and cell-free membrane patches. Pfuegers Arch 391:85100.

Harris GL, Henderson LP, Spitzer NC (1988) Changes in densities and kinetics of delayed rectifier potassium channels during neuronal differentiation. Neuron 1:739-750.

Hockberger PE, Tseng H-Y, Connor JA (1989) Fura-2 measurements of cultured rat Purkinje neurons show dendritic localization of $\mathrm{Ca}^{2+}$ influx. J Neurosci 9:2272-2284.

Hoshi T, Aldrich RW (1988) Voltage-dependent $\mathrm{K}^{+}$currents and underlying single $\mathrm{K}^{+}$channels in pheochromocytoma cells. J Gen Physiol 91:73-106.

Hounsgaard J, Midtgaard J (1988) Intrinsic determinants of firing pattern in Purkinje cells of the turtle cerebellum in vitro. J Physiol (Lond) 402:731-749.

Hounsgaard J, Nicholson C (1983) Potassium accumulation around individual Purkinje cells in cerebellar slices for the guinea-pig. J Physiol (Lond) 340:359-388.

Josephson IR, Brown AM (1986) Inwardly rectifying single-channel and whole cell $\mathrm{K}^{\prime}$ currents in ral ventricular myocytes. J Membr Biol 94:19-35.

Kapoor R, Jaeger CB, Llinas R (1989) Electrophysiology of the mammalian cerebellar cortex in organ culture. Neuroscience 26:493-507.

Kasai H, Kameyama M, Yamaguchi K, Fukuda J (1986) Single transient $\mathrm{K}$ channels in mammalian sensory neurons. Biophys J 49:12431247.

Leibowitz MD, Dionne VE (1984) Single channel acetylcholine receptor kinetics. Biophys J 45:153-163.

Llinas R (1975) Electroresponsiveness of dendrites in central neurons. In: Advances in neurology (Kreutzberg GW, ed), pp 1-13. New York: Raven.

Llinas R, Sugimori M (1980a) Electrophysiological properties of in vitro Purkinje cell somata in mammalian cerebellar slices. J Physiol (Lond) 305:171-195.

Llinas R, Sugimori M (1980b) Electrophysiological properties of in vitro Purkinje cell dendrites in mammalian cerebellar slices. J Physiol (Lond) 305:197-213.

Marty A (1981) $\mathrm{Ca}^{2+}$-dependent $\mathrm{K}^{+}$channels with large unitary conductance in chromaffin cell membranes. Nature 291:497-499.

Matsuda H, Saigusa A, Irisawa H (1987) Ohmic conductance through the inwardly rectifying $\mathbf{K}$ channel and blocking by internal $\mathbf{M g}^{2+}$. Nature 325:156-159.

Ohmori H, Yoshida S, Hagiwara S (1981) Single $\mathrm{K}^{+}$channel currents of anomalous rectification in cultured rat myotubes. Proc Natl Acad Sci USA 78:4960-4964.

Palotta BS, Magleby KL, Barrett JN (1981) Single channel recordings of $\mathrm{Ca}^{2+}$ activated $\mathrm{K}^{+}$currents in rat muscle cell culture. Nature 293: $471-474$.

Quandt FN (1988) Three kinetically distinct potassium channels in mouse neuroblastoma cells. J Physiol (Lond) 395:401-418.

Reinhart PH, Chung S, Levitan IB (1989) A family of calcium-dependent potassium channels from rat brain. Neuron 2:1031-1041.

Rogawski MA (1986) Single voltage-dependent potassium channels in cultured rat hippocampal neurons. J Neurophysiol 56:481-493.

Ross WN, Werman R (1987) Mapping calcium transients in the dendrites of Purkinje cells from the guinea-pig cerebellum in vivo. J Physiol (Lond) 389:319-336.

Rudy B (1988) Diversity and ubiquity of K channels. Neuroscience 25:729-749.

Sakmann B, Trube G (1984) Conductance properties of single inwardly rectifying potassium channels in ventricular cells from guinea-pig heart. J Physiol (Lond) 347:641-657.

Shingai R, Quandt FW (1986) Single inward rectifier channels in horizontal cells. Brain Res 369:65-74.

Solc CK, Zagotta WN, Aldrich RW (1987) Single-channel and genetic analyses reveal two distinct A-type potassium channels in Drosophila. Science 236:1094-1098.

Standen NB, Stanfield PR, Ward TA (1985) Properties of single potassium channels in vesicles formed from the sarcolemma of frog skeletal muscle. J Physiol (Lond) 364:339-358.

Storm JF (1987) Action potential repolarization and a fast after-hy- 
perpolarization in rat hippocampal pyramidal cells. J Physiol (Lond) 385:733-759.

Tank DW, Sugimori M, Connor JA, Llinas RR (1988) Spatially resolved calcium dynamics of mammalian Purkinje cells in cerebellar slice. Science 242:773-777.

Taylor PS (1987) Selectivity and patch measurement of A-current channels in Helix aspersa neurons. J Physiol (Lond) 388:437-447.

Thompson SH, Aldrich RW (1980) Membrane potassium channels. In: The cell surface and neuronal function, Vol 6 (Cotman CW, Poste G, Nicholson GL, eds), pp 49-85. Amsterdam: Elsevier.
Woodward DJ, Hoffer BJ, Lapham LW (1969) Postnatal development of electrical and enzyme histochemical activity in Purkinje cells. Exp Neurol 23:120-139.

Yool AJ, Dionne VE, Gruol DL (1988) Developmental changes in $\mathrm{K}^{+}$-selective channel activity during differentiation of the Purkinje neuron in culture. J Neurosci 8:1971-1980.

Ypey KL, Clapham DE (1984) Development of a delayed outwardrectifying $\mathrm{K}^{+}$conductance in cultured mouse peritoneal macrophages. Proc Natl Acad Sci (USA) 81:3083-3087. 